\title{
Equilibrium, Kinetic and Adsorption Mechanisms of Chromium (VI) on Characterized Activated Carbon Synthesized from Phosphoric Acid Activation of Coconut Shells
}

\author{
Hakeem Seidu, Dapeng Li, Jing Zhou \\ School of Environmental Science and Engineering, Suzhou University of Science \& Technology, Suzhou, China
}

Email address:

kimoetrail@icloud.com (Hakeem Seidu), ustsldp@163.com(DapengLi), frances.rinkey@outlook.com(Jing Zhou)

To cite this article:

Hakeem Seidu, Dapeng Li, Jing Zhou. Equilibrium, Kinetic and Adsorption Mechanisms of Chromium (VI) on Characterized Activated Carbon Synthesized from Phosphoric Acid Activation of Coconut Shells. International Journal of Environmental Monitoring and Analysis. Vol. 6, No. 3, 2018, pp. 84-94. doi: 10.11648/j.ijema.20180603.13

Received: May 15, 2018; Accepted: June 6, 2018; Published: July 25, 2018

\begin{abstract}
Over the years, water pollution due primarily to the discharge of toxic heavy metals from industrial activities has served as a major challenge in our quest to provide clean drinking water to millions of people across the world. Numerous cheap and environmentally friendly methods and technologies have been developed for the treatment of wastewater contaminated with heavy metals. Key among these technologies is the use of adsorbent as it is the most economical and efficient. In this present study, coconut shells were used to develop microporous adsorbent (activated carbon) through chemical activation by phosphoric acid $\left(\mathrm{H}_{3} \mathrm{PO}_{4}\right)$. An analysis of the effect of various process parameters such as $\mathrm{pH}$, temperature, initial metal ion concentration, adsorbent dose and contact time was conducted through batch adsorption of hexavalent chromium $[\mathrm{Cr}$ (VI)] on prepared AC sample. Initial $\mathrm{Cr}(\mathrm{VI})$ concentration was investigated through a range of $10-50 \mathrm{mg} / \mathrm{L}$ with the study showing an optimum concentration for $\mathrm{AC}$ of $20 \mathrm{mg} / \mathrm{L}$ for percentage removal (93.3\%) but adsorption capacity $\left(\mathrm{Q}_{\mathrm{e}}\right)$ was highest for $50 \mathrm{mg} / \mathrm{L}(4.512 \mathrm{mg} / \mathrm{g})$. The optimum conditions for adsorbent dose, contact time and temperature were determined as $6 \mathrm{~g} / \mathrm{L}, 100$ minutes and $30^{\circ} \mathrm{C}$ respectively for the prepared AC. Maximum adsorption was recorded for $\mathrm{pH}(2)$ at $88.25 \%$ (removal) and $4.41 \mathrm{mg} / \mathrm{g}$ (adsorption capacity) for AC. The experimental data obtained were modelled using various isotherms, including adsorption equilibrium isotherms, adsorption kinetic study and adsorption mechanisms with positive correlations (better fit) obtained for Freundlich isotherm, D-R isotherm (slightly), pseudo-second-order kinetic and Boyd models.
\end{abstract}

Keywords: Activated Carbon, Adsorption, Adsorption Capacity, Percentage Adsorption, Isotherms, Equilibrium, Kinetic, Models

\section{Introduction}

The presence of hazardous heavy metals and metalloids, especially in aqueous media is an important environmental and social problem. The extent of toxicity caused by these elements is of considerable concern worldwide because of their environmental and health burden [1]. Heavy metal toxicity can cause damage or reduce mental and central nervous functions, energy levels, blood composition and other relevant vital organs. Exposure in the long term may result in the adverse effect to physical, muscular, and neurological degenerative processes. It also has the potential to cause Parkinson's disease, multiple sclerosis and muscular dystrophy. Some heavy metals or their compounds may even cause cancer [2]. Adverse alteration of water quality presently produces large-scale illness and deaths, accounting for approximately 50 million deaths per year worldwide, most of these deaths occurring in Africa and Asia. As, ultimately, heavy metal regulations for drinking water and wastewater become stricter, the conventional means of water treatment becomes either costly or inefficient [3].

The past few decades has seen the development of cheap and environmentally friendly technologies for the treatment of wastewater generated both industrially and domestically. 
In this regard, methods like ion-exchange, membrane filtration, microbe-assisted phyto-bioremediation and nanomaterials have been developed and demonstrated to be successful, though at high capital and operational costs. One technology that has proven to overcome such disadvantages is the adsorptive removal of metal ions by various adsorbents. Activated carbons (AC) are very effective adsorbents due to their high surface area and pore volume [4]. It has been shown that lignocellulosic agricultural wastes, particularly nutshells are very good precursors for the production of $\mathrm{AC}$ to remove heavy metal ions from aqueous solutions. Huge amounts of coconut shells are generated as agricultural wastes in Ghana, which when analyzed show significant lignin (macropores yielding) and cellulose (micropores yielding) dominance. Regardless of these vast quantities of such resources, a significant amount of AC used in the country for both industrial and wastewater treatment is imported from Japan and Germany. The utilization of these low-cost agricultural wastes as carbon precursor is very promising, but their use as metal ion scavenger is rare [3]. These, therefore present an opportunity to both eliminate such waste in the environment and also control increasing heavy metal contamination in our waterbodies. The purpose of this study is to evaluate the suitability of prepared acidimpregnated activated carbon derived from locally sourced coconut shell waste as an adsorbent in the removal of heavy metal ions and evaluate the various mechanisms (equilibrium, kinetic and adsorption) that control the adsorption process whilst also determining the effect of various process parameters such as $\mathrm{pH}$, adsorbent dose, initial metal ion concentration, contact time and temperature on the removal efficiency of the prepared AC.

\section{Experimental}

\subsection{Materials}

The carbonaceous raw material used for the preparation of the AC sample is coconut shells sourced from Ghana. Washed and cleaned shells were sundried for 2 weeks to facilitate easy crushing and grinding. The dried shells were sieved $(1.0-1.5 \mathrm{~mm})$. All chemical reagents were of analytical grade.

\subsection{Synthesis of Activated Carbon}

The cleaned and grind precursor was dried at $110^{\circ} \mathrm{C}$ for 24 hrs. It was subsequently impregnated with an appropriate amount of $30 \% \mathrm{H}_{3} \mathrm{PO}_{4}$ for $12 \mathrm{hrs}$ in a hot air oven to achieve adequate penetration into the interior precursor. A specified amount of was then transferred into a $150 \mathrm{~mm} \times 40 \mathrm{~mm}$ stainless steel reactor and placed inside an electric horizontal tubular furnace controlled by a PID controller. The temperature of the reaction zone was measured by the chromel-alumel thermocouple and pyrolysis carried out under a continuous flow of $\mathrm{N}_{2}$ gas $(200 \mathrm{~mL} / \mathrm{min})$ to obtain AC sample of carbonization temperature, $400^{\circ} \mathrm{C}$. The carbonized sample is then cooled to room temperature under an inert atmosphere and washed with water and dilute $\mathrm{NaOH}$ until the $\mathrm{pH}$ value is neutral. The $\mathrm{AC}$ obtained was labelled AC400. Figure 1A presents a schematic of the process description.

\subsection{Characterization of AC Sample}

$\mathrm{N}_{2}$ adsorption-desorption (A-D) isotherms on AC400 were conducted in an automatic adsorption unit (ADU) at $-195^{\circ} \mathrm{C}$ liquid nitrogen temperature. The process involves an initial removal of adsorbed moisture and impurities on the surface through degassing at $200{ }^{\circ} \mathrm{C}$ for $5 \mathrm{hrs}$. $S_{\mathrm{T}}$ value was determined experimental through adsorption isotherm over relative pressure by the standard $B E T$ method. The $V_{T}$ of the sample were determined as the total volume of $\mathrm{N}_{2}$ gas adsorbed at high relative pressure (0.995) [5]. The $S_{m i}$ and $V_{m i}$ were determined by applying D-R equation [6].

Surface functional groups of the AC sample were determined by infrared (FTIR) spectroscopy analysis using spectra range of $4000-400 \mathrm{~cm}^{-1}$. The surface morphology of the AC sample was analyzed by a SEM and the extent of graphitization determined by $\mathrm{x}$-ray diffractometer $(X R D)$.

\subsection{Adsorption of Cr (VI) Ions}

A stock solution of $\mathrm{Cr}$ (VI) was prepared by mixing a known amount of $\mathrm{K}_{2} \mathrm{Cr}_{2} \mathrm{O}_{7}$ in distilled water and stirring to gain homogeneity and various concentrations of the eventual solution were obtained. Varying amounts of AC was mixed with each initial concentration of metal ions and agitated at $120 \mathrm{rpm}$ for 180 minutes with varying temperatures $(20-$ $\left.60^{\circ} \mathrm{C}\right)$ and $\mathrm{pH}(2-11)$ adjusted using a thermal shaker and $\mathrm{pH}$ meter. After each experiment, the spent AC were filtered out using Whatman filter paper and the concentration of the resulting solution was determined using UV Spectrophotometer at $540 \mathrm{~nm}$ by complexing $\mathrm{Cr}$ (VI) with $\mathrm{C}_{13} \mathrm{H}_{14} \mathrm{~N}_{4} \mathrm{O}$ [7].

\section{Results and Discussions}

\subsection{Characterization of $A C$}

\subsubsection{Gas Sorption Isotherm of AC400}

The $\mathrm{N}_{2}$ A-D isotherm of the AC400 was carried out to investigate the porous characteristics. The holding time of 1 hour at final carbonization temperature was maintained. Figure 1B depicts the isotherm of AC400 which presents well-developed porosity of sample. The $\mathrm{N}_{2}$ adsorption capacity of the AC400 was determined as $501.5 \mathrm{cc} / \mathrm{g}$.

\subsubsection{FTIR Spectroscopy}

From Figure $1 \mathrm{C}$, the spectrum is shown to have numerous functional groups attached. These include high broad peaks at approximately 3423 and $2851 \mathrm{~cm}^{-1}$ assigned to the presence of $\mathrm{O}-\mathrm{H}$ groups (adsorbed moisture) and $\mathrm{sp}^{3} \mathrm{C}-\mathrm{H}$ stretching respectively. Also observed were peaks at around 1601,1363 and $1076 \mathrm{~cm}^{-1}$ indicating the presence of $\mathrm{C}=\mathrm{C}$ in rings, $\mathrm{O}-\mathrm{C}$ groups, $\mathrm{sp}^{2} \mathrm{C}-\mathrm{H}$ stretching and $\mathrm{O}-\mathrm{H}$ functional groups respectively. A little shift of the bands corresponding 
to Silane groups was also observed. The presence of amine groups is confirmed by the peaks observed within the range of $1190-1130 \mathrm{~cm}^{-1}$ and are due to the $\mathrm{C}-\mathrm{N}$ stretching. Also revealed were hydrocarbon groups observed at peaks corresponding to a range of 600-900. These hydrocarbon groups are revealed to be deformed, bend or ring puckering.

\subsubsection{Morphology of $A C$}

SEM micrographs of AC400 shows well-developed porous surfaces at higher magnification. The pores from SEM images were observed as having sizes in the micrometer $(\mu \mathrm{m})$ range and are considered as channels to the microporous network. It can also be observed that the adsorbent has a rough texture with heterogeneous surface and a variety of randomly distributed pore sizes as shown in Figure 1D.

\subsubsection{XRD Analysis}

The sample show general broad peaks and absence of sharp peak which reveal a predominantly amorphous structure, which is an advantageous property for well-defined porous adsorbents [8]. At $24^{\circ}$, the broad peaks observed (Figure 1E) illustrates the non-graphitized nature of AC400 which indicates high microporous structures [9] which was confirmed by the gas adsorption isotherms.

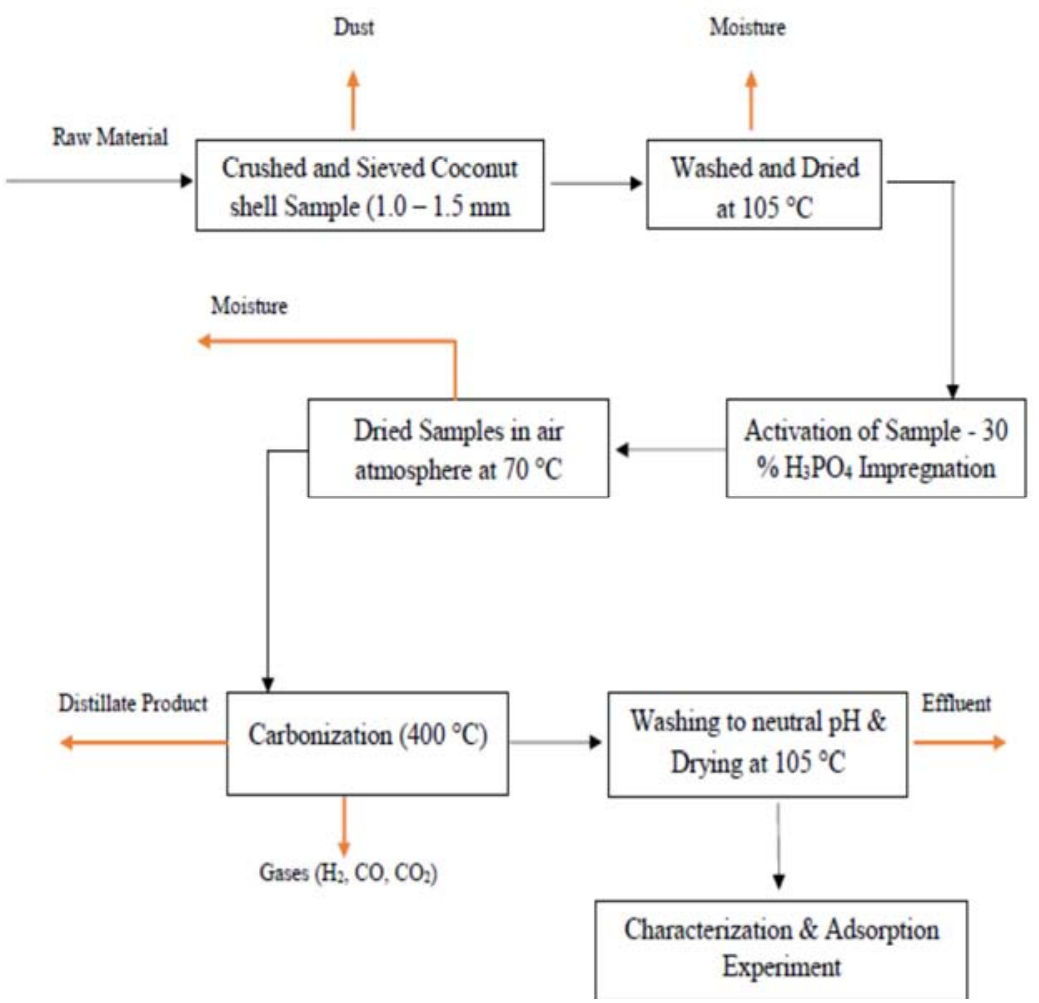

A: Process Flow Diagram for Preparing AC Sample

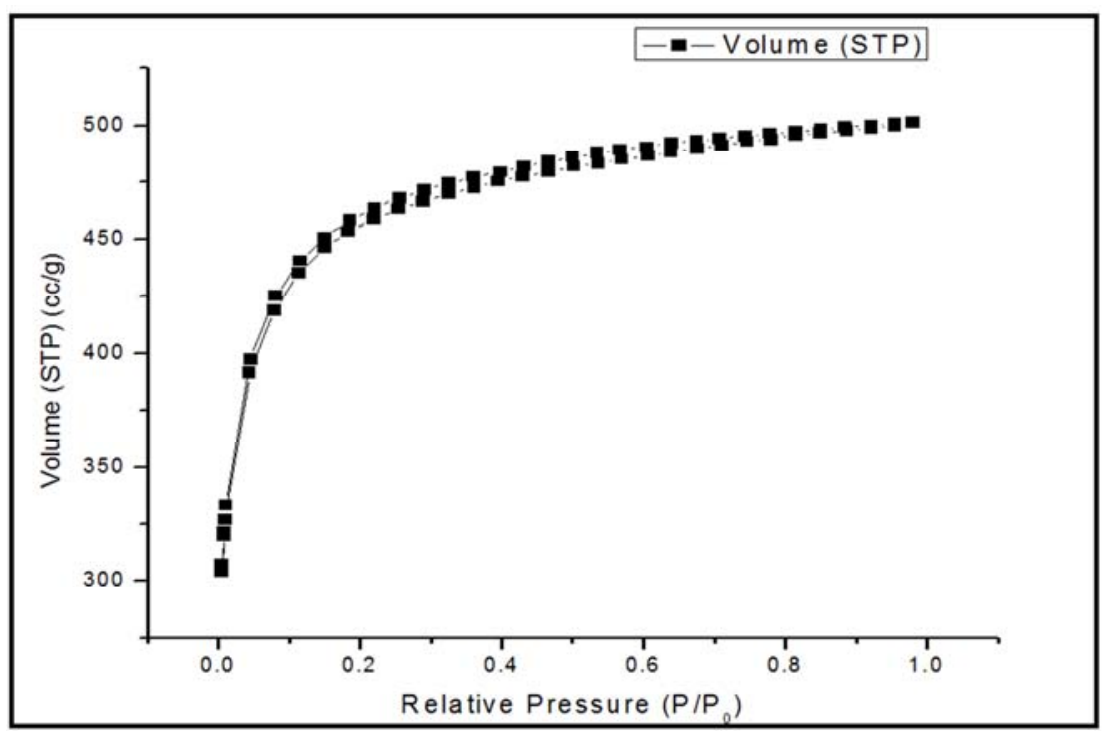

B: Isotherm for AC sample (AC400) 


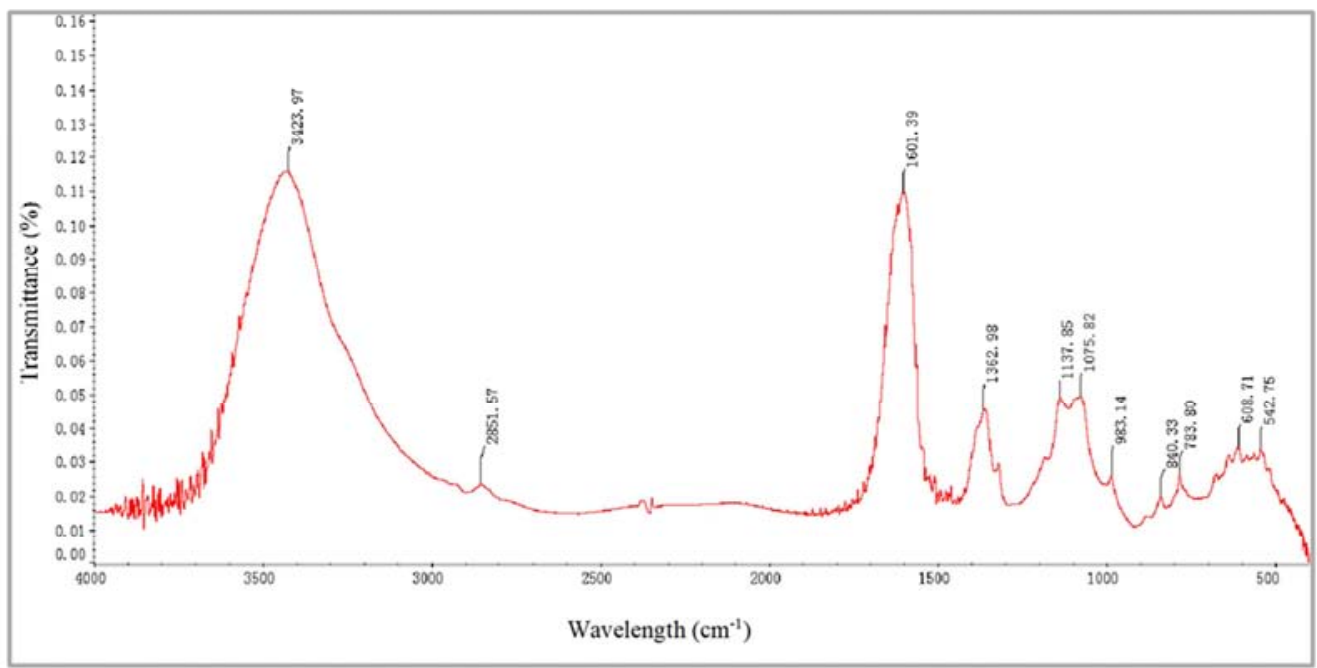

C: Graphical Representation of FTIR Results for AC sample (AC400)

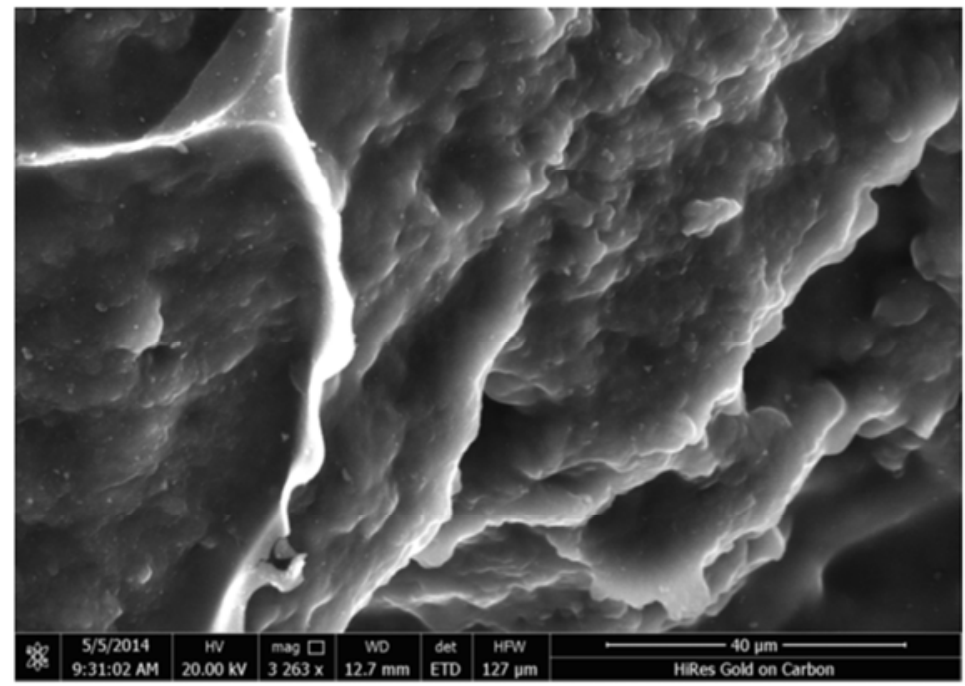

D: Micrograph for AC400

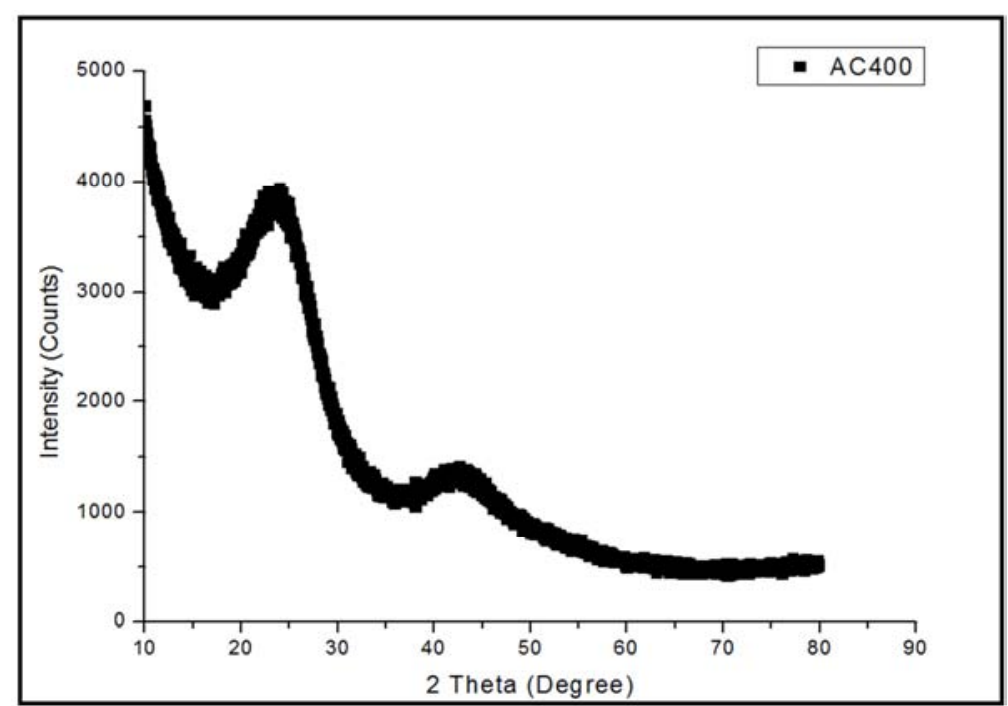

E: Graphical Representation of XRD results for AC sample (AC400)

Figure 1. (A-E) Graphical Illustration of AC400 Characterization Results. 


\subsection{Effect of Process Parameters on Cr(VI) Adsorption}

\section{(1). Initial Cr (VI) Concentration}

For AC400, the adsorption of chromium (VI) ions illustrates an initial rise in percentage removal from $93.3 \%$ for $10 \mathrm{mg} / \mathrm{L}$ of metal ion to $93.9 \%$ for $20 \mathrm{mg} / \mathrm{L}$. However, there is a downward trend for $30 \mathrm{mg} / \mathrm{L}, 40 \mathrm{mg} / \mathrm{L}$ and 50 $\mathrm{mg} / \mathrm{L}$ corresponding to $92.93,91.68$ and $90.24 \%$ respectively, as illustrated in Figure 2A, with certain experimental conditions held constant ( $(\mathrm{pH}-2.0$, time-180 minutes, temp.$30^{\circ} \mathrm{C}$, adsorbent dose $\left.-10 \mathrm{~g} / \mathrm{L}\right)$.

The Plot for the rate of adsorption by AC400 (Figure 2B) clearly provides evidence to prove that the equilibrium time and adsorbate amount are dependent. The equilibrium time is also shown to exist between 80 to 180 minutes at increasing initial $\mathrm{Cr}$ (VI) concentration. From the experiment, it is highlighted that adsorption of the metal ions is instantaneous within the initial 20 minutes and proceeded to increase as time progressed. Invariably, it is postulated that more unoccupied sites within the adsorbent (AC400) surface accounted for the little difference in the final percentage adsorption observed from $10-50 \mathrm{gm} / \mathrm{L}$. Therefore, the initial high adsorption recorded can be attributed to the increased concentration gradient of aqueous metal ions and the presence of numerous vacant sites on the surface of the adsorbent at the start of the experiment. As a result of the limited mass transfer of the metal ions from the liquid phase to the surface of the adsorbent, the adsorptive removal increased linearly with contact time, with equilibrium reached when mass transfer slows within the adsorbent particles [10].

\section{(2). Effect of Adsorbent Dose (AD)}

Varying doses of AC400 (1-10 g/L) were studied with the process parameters kept constant; initial $\mathrm{Cr}$ (VI) concentration $-30 \mathrm{mg} / \mathrm{L}$, and presented in Figure $2 \mathrm{C}$. It can be observed that the maximum adsorption was achieved with 10 $\mathrm{g} / \mathrm{L}$ of adsorbent at $92.93 \%$. The percentage removal declined with decreasing adsorbent dose from $92.6 \%$ to 20.43 for 6 $\mathrm{g} / \mathrm{L}$ to $1 \mathrm{~g} / \mathrm{L}$. For $\mathrm{Q}_{\mathrm{e}}$, the results show a decline at a lower adsorbent dose of $1 \mathrm{~g} / \mathrm{L} 6.13 \mathrm{mg} / \mathrm{g}(1 \mathrm{~g} / \mathrm{L})$ to $5.06 \mathrm{mg} / \mathrm{g}(2$ $\mathrm{g} / \mathrm{L})$ with a subsequently rise to $5.818 \mathrm{mg} / \mathrm{g}(4 \mathrm{~g} / \mathrm{L})$ and a decrease to $4.63 \mathrm{mg} / \mathrm{g}(6 \mathrm{~g} / \mathrm{L})$ and $2.788 \mathrm{mg} / \mathrm{g}(10 \mathrm{~g} / \mathrm{L})$.

Figure 2D presents the rate of $\mathrm{Cr}(\mathrm{VI})$ adsorption on varying adsorbent doses. The adsorption was observed to exhibit a significant rise between 60-80 minutes during the experiment with increasing contact time. This however tapered off after 80 minutes to present an equilibrium adsorption point where no significant rise was observed, especially with regard to higher adsorbent dose (10, 6 and $4 \mathrm{~g} / \mathrm{L})$.

(3). Effect of $p H$

The $\mathrm{pH}$ of the solution is very important to the adsorption process [16] with various levels of $\mathrm{pH}(2.0-11.0)$ employed for this study. The other parameters were kept under constant conditions; temp. $\left(30^{\circ} \mathrm{C}\right)$, contact time $(180$ minutes), initial $\mathrm{Cr}(\mathrm{VI})$ conc. $(10 \mathrm{mg} / \mathrm{L})$ and adsorbent dose $(2 \mathrm{~g} / \mathrm{L})$. The dependence of $\mathrm{Cr}(\mathrm{VI})$ adsorption on $\mathrm{pH}$ can largely be related to the type and ionic state of the functional groups present on the surface of adsorbent and as well as the metal chemistry in the solution. The trend in adsorption observed in Figure 2E show a higher percentage removal of $\mathrm{Cr}$ (VI) at acidic $\mathrm{pH}$, specifically, 2.0 and 4.0, reaching $88.2 \%$ and $86.9 \%$ respectively. Subsequently, there was a significant decline at $\mathrm{pH}>4$ where percentage removal results obtained for $\mathrm{pHs}$ values of $6.5,9$ and 11 of $74.7 \%, 48.9 \%$ and 36.2 respectively with corresponding values of $4.335 \mathrm{mg} / \mathrm{g}, 4.215 \mathrm{mg} / \mathrm{g}$ and $3.615 \mathrm{mg} / \mathrm{g}$.

At low $\mathrm{pH}$, the adsorption is relatively high as a result of available $\mathrm{Cr}$ (VI) in different forms and also attributed to the surface groups within the surface of the adsorbent. Low $\mathrm{pH}$ (acidic) presents a situation where the predominant species of $\mathrm{Cr}$ (VI) are $\mathrm{HCrO}_{4}^{-}$and $\mathrm{Cr}_{2} \mathrm{O}_{7}^{2-}$ but presents $\mathrm{CrO}_{4}^{2-}$ as the only stable species at neutral $\mathrm{pH}$ [11]. There is an equilibrium shift to dichromate when there is a decrease in the $\mathrm{pH}$ range of $2-4$, according to the overall equilibrium as follows:

$$
2 \mathrm{CrO}_{4}^{2-}+2 \mathrm{H}^{+} \rightarrow \mathrm{Cr}_{2} \mathrm{O}_{7}^{2-}+\mathrm{H}_{2} \mathrm{O}
$$

Also, there is greater competition between $\mathrm{OH}^{-}$and $\mathrm{CrO}_{4}^{2-}$ ions as the $\mathrm{pH}$ increases towards neutral with the former acting as the dominant species. This reduction in net positive surface potential causes a decline in the electrostatic forces between metal ion species and the adsorbent which results in a decreased adsorption capacity. The rate of removal at varying $\mathrm{pH}$ is illustrated in Figure $2 \mathrm{~F}$.

(4). Effect of Temperature

According to the results presented (Figures $2 \mathrm{G} \& 2 \mathrm{H}$ ), there is a steady rise in both adsorption percentage (\%) and adsorption capacity $\left(\mathrm{Q}_{\mathrm{e}}\right)$ with temperature. The increase in percentage adsorption of $\mathrm{Cr}$ (VI) by AC400 indicates an endothermic process. At higher temperatures, the rate of diffusion of solute within the pores of the AC400 increases since diffusion is endothermic. Thus, the percentage adsorption of $\mathrm{Cr}$ (VI) increases as the rate of diffusion of $\mathrm{Cr}$ (VI) ions in the external mass transport process increases with temperature [12]. There is, however, little or no significant effect on the percentage adsorption.

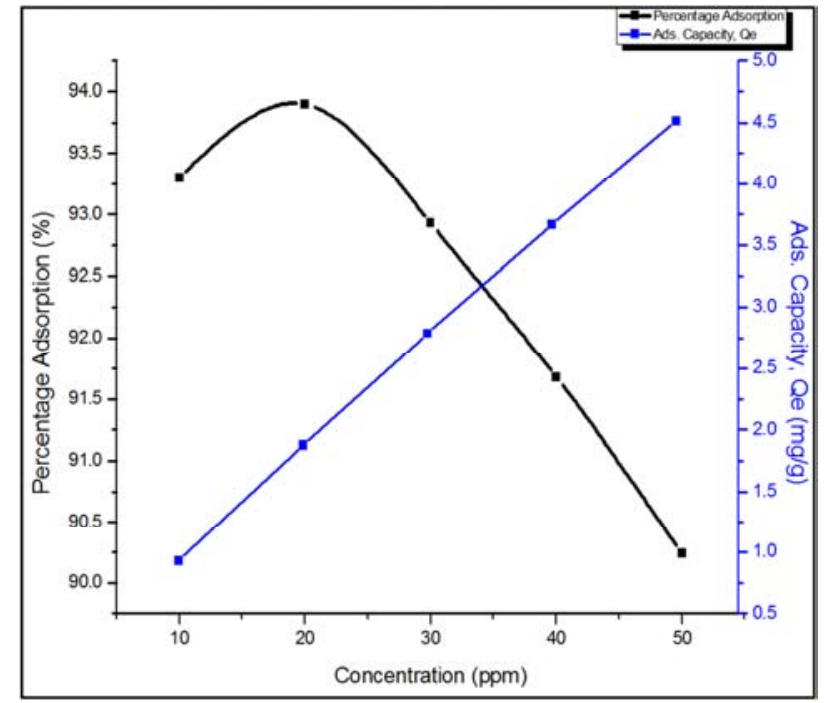

A 


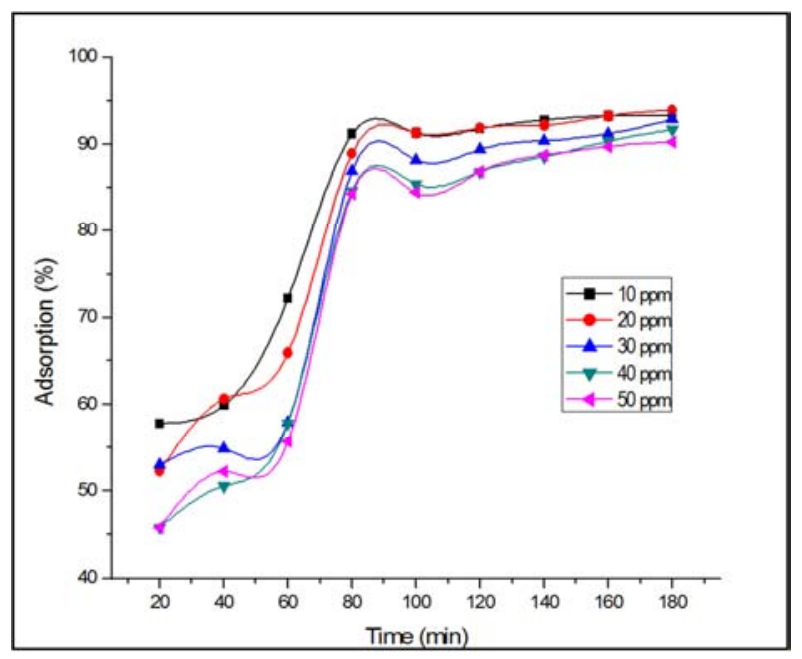

B
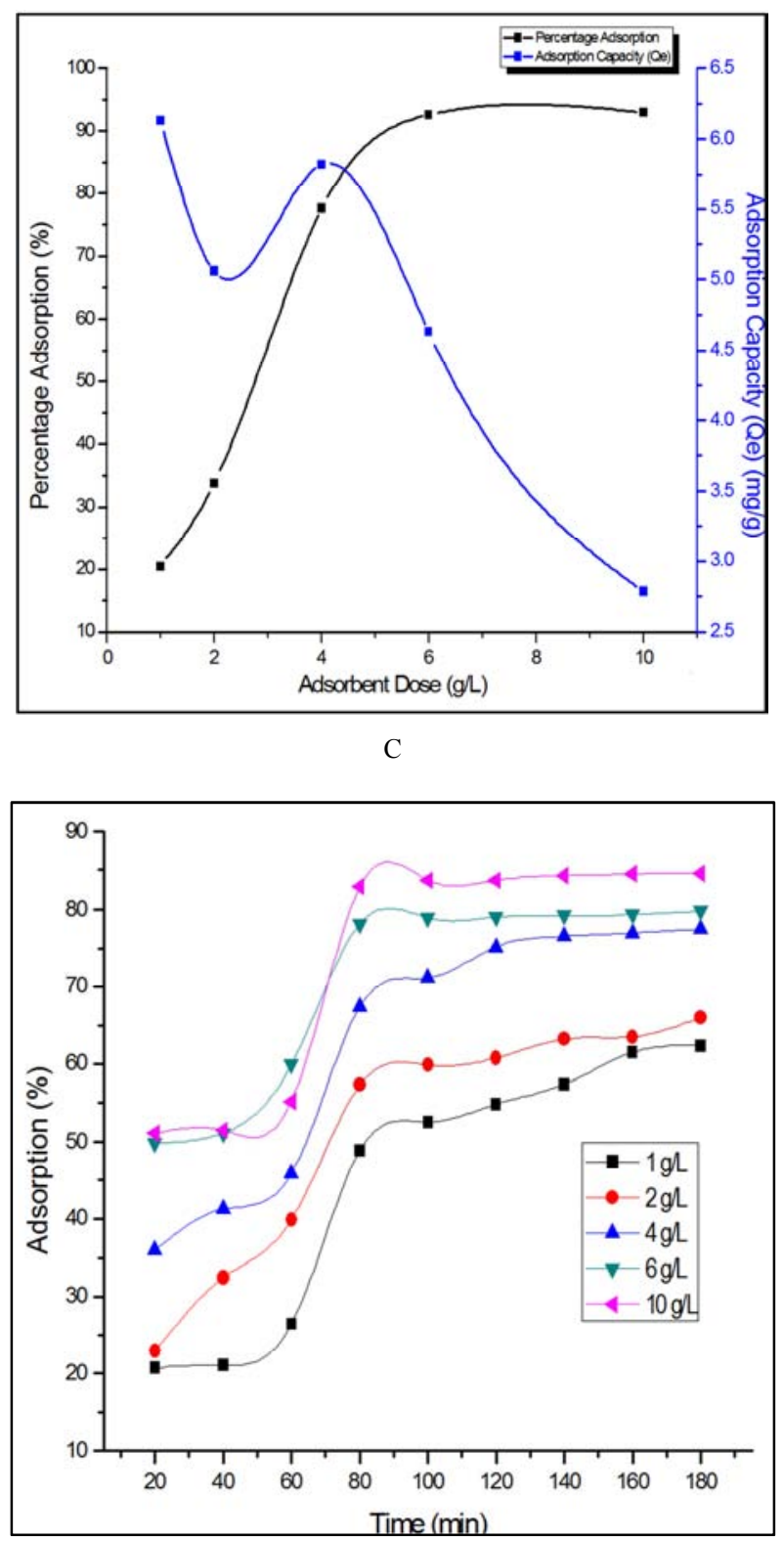

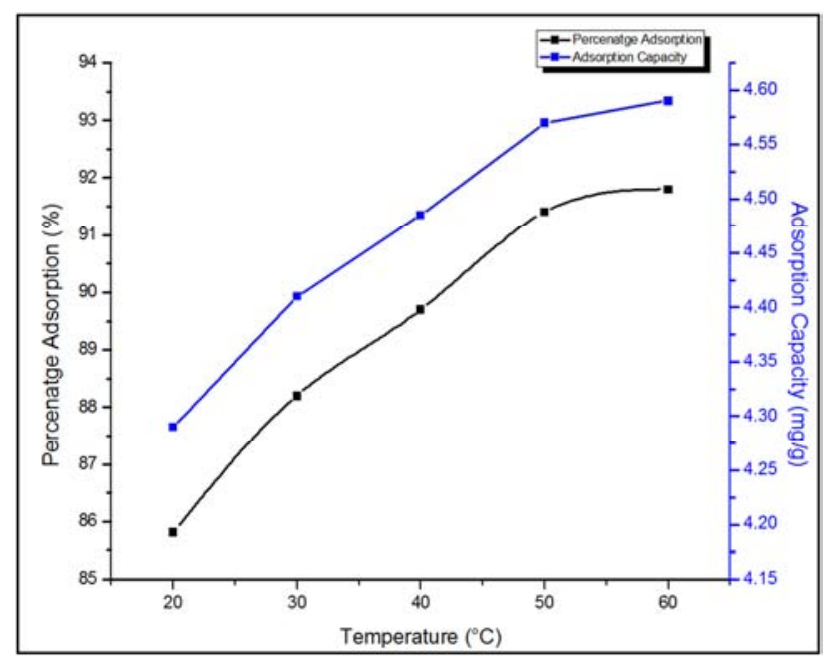

E

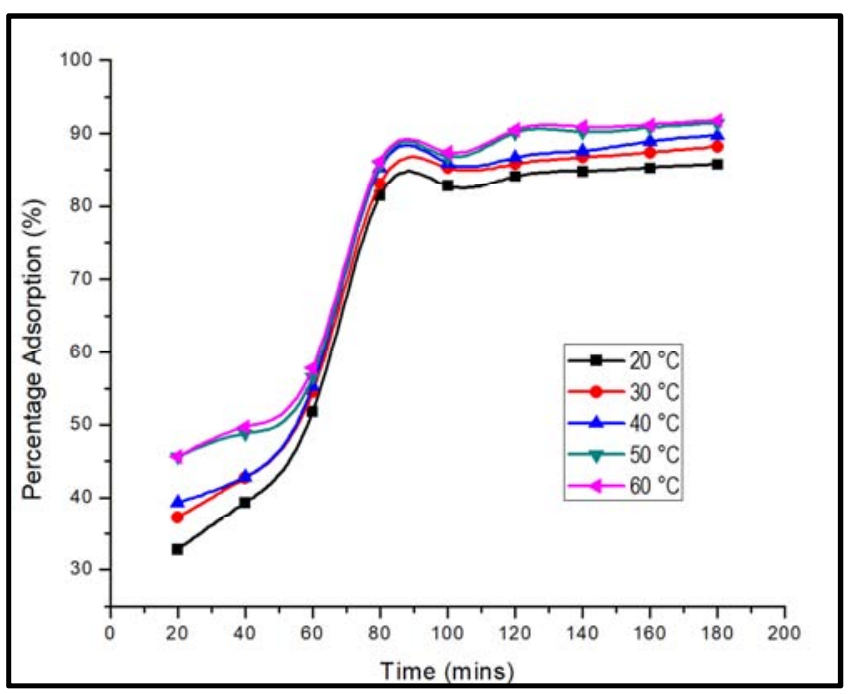

$\mathrm{F}$

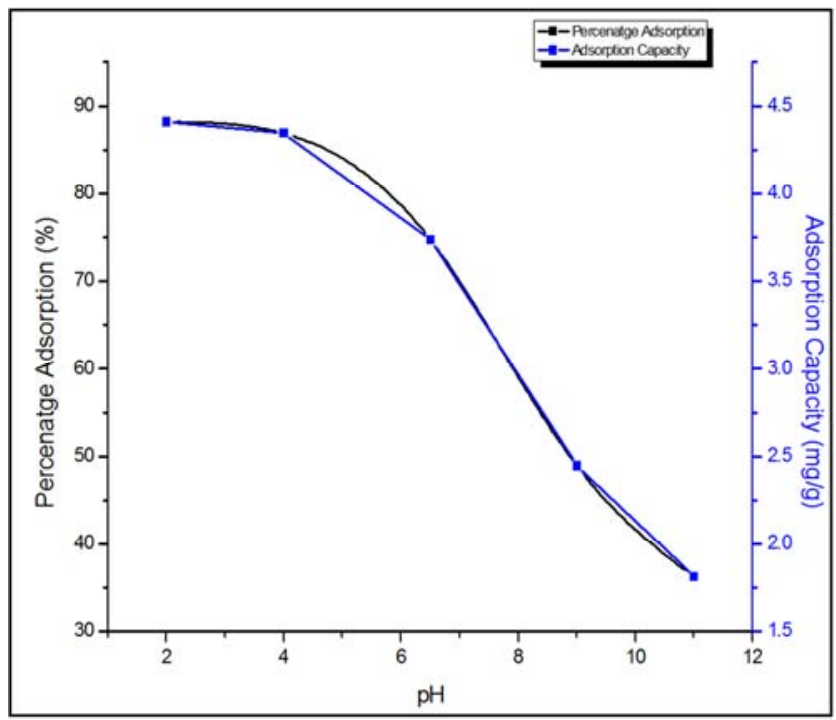

G 


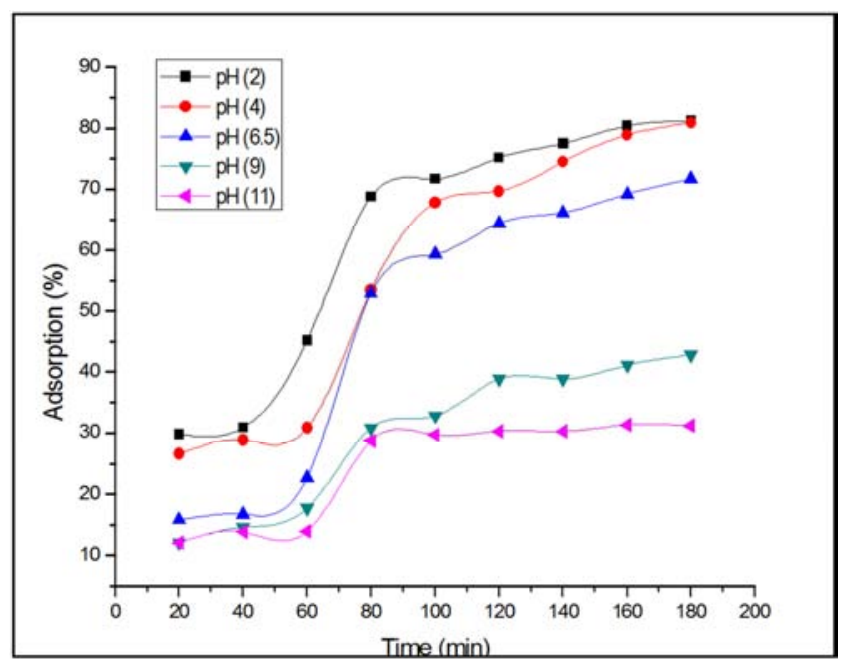

$\mathrm{H}$

Figure 2. $(A-H)$ Adsorption experimental data (A: Effect of initial Cr (VI) conc., B: Removal rate at varying initial $\mathrm{Cr}$ (VI) conc., C: Effect of Adsorbent dose, D: Removal rate at varying adsorbent dose, E: Effect of temperature, $F$ : Removal rate at varying temperature, $G$ : Effect of $\mathrm{pH}, \mathrm{H}$ : Removal rate at varying $\mathrm{pH}$ )

\subsection{Modelling of Relevant Isotherms}

\subsubsection{Adsorption Equilibrium Isotherms}

The Langmuir, Freundlich, Temkin, and $D-R$ isotherms are the most frequently used models to describe the experimental data of adsorption.

\section{(1). Langmuir Isotherm}

Langmuir isotherm presents the interaction between adsorbate and adsorbent. It is essential for the design of adsorption process as it is applicable to homogeneous adsorption processes where each adsorbate on to the surface has equal adsorption activation energy. The linear form is provided as:

$$
\frac{C_{e}}{q_{e}}=\frac{1}{K_{L}}+\frac{a_{L}}{K_{L}} C_{e}
$$

Plotting $C_{e} / q_{e}$ versus $\mathrm{C}_{\mathrm{e}}$ shows that the adsorption data for AC400 fitted to the Langmuir isotherm as presented in Figure 3A. The theoretical monolayer saturation capacity, $\mathrm{Q}_{0}$ was also calculated as $\mathrm{Q}_{\mathrm{o}}=K_{L} / a_{L}$. Table 1 presents the calculated Langmuir constants for the experimental data.

The positive value obtained for $a_{L}$ indicates the suitability of Langmuir model to explain the $\mathrm{Cr}$ (VI) adsorption using AC400. The separation factor $\left(R_{L}\right)$ which examines the feasibility of the adsorption process for the developed AC. The positive value of $R_{L}\left(0<R_{L}<1\right)$ obtained for the experiment indicates that the adsorption process was clearly feasible.

\section{(2). Freundlich Isotherm}

For heterogeneous surfaces, this model is the most relevant model especially for multilayer adsorption isotherm and is generally characterized by the heterogeneity factor $(1 / n)$. The expression applied to the experimental data for the linear form of Freundlich isotherm is;

$$
\text { In } \mathrm{Q}_{\mathrm{e}}=\operatorname{In} \mathrm{K}_{\mathrm{F}}+\frac{1}{n} \operatorname{In} \mathrm{C}_{\mathrm{e}}
$$

A plot of In $Q_{e}$ against In $C_{e}$ shown in Figure 3B, provided for the calculation of the slope and intercept. The intercept $\left(\mathrm{In} \mathrm{K}_{\mathrm{F}}\right.$ ) is a measure of adsorption capacity with adsorption intensity $\left(\frac{1}{n}\right)$ as the slope and presented in Table 1 .

Freundlich isotherm describes reversible adsorption and is generally not restricted to the formation of a monolayer. Freundlich constant $\left(\mathrm{K}_{\mathrm{F}}\right), 3.246\left[(\mathrm{~mol} / \mathrm{g})(\mathrm{mol} / \mathrm{L})^{\mathrm{n}}\right]$ confirmed a significantly high adsorption capacity of $\mathrm{Cr}$ (VI). The magnitude of $n$ resulting from the heterogeneity factor $\left(\frac{1}{n}\right)$ is an indication of the favourability of the adsorption. Generally, it is known that the value of $n$ in the range [2-10] represent good, [1 - 2] represents moderately good, < 1 represents poor adsorptive characteristics [13]. Based on the value of 5.57 obtained for $n$, it can be postulated as having good adsorption characteristics.

Based on the correlation coefficients, $\mathrm{R}^{2}$ obtained for Langmuir isotherm (0.973) and Freundlich isotherm (0.991), it can be stated that Freundlich isotherm presents a better fit for AC400 in the adsorption of $\mathrm{Cr}$ (VI) than Langmuir isotherm.

(3). Dubinin - Radushkevich (DR) Isotherm

The DR equation is essentially utilized for the description of microporous adsorbent materials. The equation used for $\mathrm{D}-\mathrm{R}$ isotherm of experimental data is presented as;

$$
\operatorname{In} \mathrm{Q}_{\mathrm{e}}=\operatorname{In} \mathrm{Q}_{\mathrm{D}}-2 \mathrm{~B}_{\mathrm{D}} \mathrm{RT} \operatorname{In}\left(1+1 / C_{e}\right)
$$

A graph was plotted for In $\mathrm{Q}_{\mathrm{e}}$ against RT In $\left(1+1 / \mathrm{C}_{\mathrm{e}}\right)$ and the straight line was determined by the method of best fit with relatively high regression as illustrated in Figure 3C. From the graph, the apparent energy used to determine the type of adsorption process was calculated using the equation;

$$
E=\frac{1}{\sqrt{2 B_{D}}}
$$

Table 1 presents the results of the D-R isotherm constants.

The activation energy provides insight into the undergoing process of adsorption although it is not necessarily supported in determining the rate controlling step. For adsorption process in the nature of physisorption, $E<8 \mathrm{~kJ} / \mathrm{mol}$, and ion exchange, $E$ exist within the range of $8-18 \mathrm{~kJ} / \mathrm{mol}$ [14]. Alternatively, for film-diffusion-controlled process, $E<16$ $\mathrm{kJ} / \mathrm{mol}$, particle diffusion - controlled, $E$ is $21-38 \mathrm{~kJ} / \mathrm{mol}$, and chemical-reaction-controlled, $E>50 \mathrm{~kJ} / \mathrm{mol}$ [15]. The Apparent Energy (E) value used to adsorb $\mathrm{Cr}$ (VI) at $30^{\circ} \mathrm{C}$ was $0.0843 \mathrm{KJ} / \mathrm{mol}$, thus confirming that the process is physisorption and considering it is less than $16 \mathrm{KJ} / \mathrm{mol}$, it can be classified as film diffusion controlled. The value of $\mathrm{R}^{2}$ obtained from the graph plotted (0.9354) indicates that the adsorption data is slightly consistent with Dubinin Radushkevich isotherm.

\section{(4). Temkin Isotherm}

Temkin isotherm assumes the heat of adsorption decreases linearly with higher coverage. Temkin isotherm possesses a factor that accounts for the adsorbent - adsorbate 
interactions. Generally, the model relies on the assumption that the heat of adsorption, which is a function of temperature, within the layer will decrease linearly rather than logarithmically with coverage [16]. The equation applied for experimental data to determine the suitability of Temkin isotherm in explaining the interactions between adsorbent and adsorbate.

$$
Q_{e}=B_{T} \operatorname{In} A_{T}+B_{T} \operatorname{In} C_{e}
$$

A plot of $\mathrm{Q}_{\mathrm{e}}$ against In $\mathrm{C}_{\mathrm{e}}$ presented a linear graph as illustrated in Figure 3D. Also, the results of calculated Temkin isotherm constants are presented in Table 1.

The heat of adsorption, $\mathrm{B}_{\mathrm{T}}$ was determined as a positive value which indicates that the physical adsorption process is exothermic which is inconsistent with obtained results. The relatively high variation of $\mathrm{R}^{2}$ obtained $(0.917)$ from unity (1.0) shows that the adsorption data does not follow Temkin isotherm.

Table 1. Equilibrium Isotherm constants for Langmuir, Freundlich, D-R and Temkin for $\mathrm{Cr}$ (VI) on AC400.

\begin{tabular}{ll}
\hline Isotherm Parameters & Isotherm Constants \\
\hline Langmuir & \\
$\mathrm{K}_{\mathrm{L}}(\mathrm{L} / \mathrm{g})$ & 4.455 \\
$\mathrm{a}_{\mathrm{L}}(\mathrm{L} / \mathrm{mol})$ & 0.73 \\
$\mathrm{Q}_{\mathrm{o}}(\mathrm{mg} / \mathrm{g})$ & 6.10 \\
$\mathrm{R}_{\mathrm{L}}$ & 0.044 \\
$\mathrm{R}^{2}$ & 0.973 \\
Freundlich & \\
$\mathrm{K}_{\mathrm{F}}\left[(\mathrm{mol} / \mathrm{g})(\mathrm{mol} / \mathrm{L})^{\mathrm{n}}\right]$ & 3.276 \\
Heterogeneity Factor $(1 / n)$ & 0.17939 \\
$\mathrm{n}$ & 5.57 \\
$\mathrm{R}^{2}$ & 0.991 \\
$\mathrm{D}^{2} \mathrm{R}$ & \\
$\mathrm{B}_{\mathrm{D}}\left(1 /(\mathrm{J} / \mathrm{mol})^{2}\right) \times 10000$ & 1.406 \\
$\mathrm{Q}_{\mathrm{D}}(\mathrm{mg} / \mathrm{g})$ & 6.732 \\
$\mathrm{E}(\mathrm{KJ} / \mathrm{mol})$ & 0.0843 \\
$\mathrm{R}^{2}$ & 0.935 \\
$\mathrm{Temkin}_{\mathrm{B}_{\mathrm{T}}-\mathrm{Slope}}$ & 0.839 \\
$\mathrm{~A}_{\mathrm{T}}(\mathrm{L} / \mathrm{mg})$ & 39.915 \\
$\mathrm{R}^{2}$ & 0.917 \\
\hline
\end{tabular}

\subsubsection{Adsorption Kinetic Study}

The importance of adsorption kinetics cannot be overstated as the rate and mechanism of adsorption can be determined from kinetic studies. Adsorption kinetic study seeks to determine the efficiency of adsorption. The kinetics study is defined as the rate of solute removal that controls the residence time of the adsorbate in solution - solute interface.

(1). Lagergren Pseudo First Order Kinetic Model

Two vital relevant for adsorption are the mechanism and the reaction rate. The residence time required for completing the reaction is determined by the solute uptake and enumerated from kinetic analysis. Lagergren, in 1898, postulated the first order rate equation for ocalic acid and malonic acid adsorption onto charcoal to describe the liquidsolid interactions based on solid capacity as

$$
\log \left(\mathrm{Q}_{\mathrm{e}}-\mathrm{Q}_{\mathrm{t}}\right)=\log \mathrm{Q}_{\mathrm{e}^{-}} k_{1} / 2.303 t
$$

A plot of $\log \left(\mathrm{Q}_{\mathrm{e}}-\mathrm{Q}_{\mathrm{t}}\right)$ against time (minutes) is illustrated in Figure 3E, with calculated pseudo-first-order kinetics constants presented in Table 2.

The $\mathrm{R}^{2}$ values $[\mathrm{pH}(2)=0.934, \mathrm{pH}(4)=0.911, \mathrm{pH}(6.5)=$ $0.911, \mathrm{pH}(9)=0.911, \mathrm{pH}(11)=0.929]$ as shown suggest that the $\mathrm{Cr}$ (VI) adsorption on AC400 does not fit well with the pseudo-first-order kinetics. Therefore, the experimental data obtained cannot be attributed to the control of boundary layer over the adsorption of $\mathrm{Cr}(\mathrm{VI})$ at the initial stages of the process [17].

\section{(2). Pseudo Second Order (PSO) Kinetic Model}

$P S O$ kinetic model was also considered for the $\mathrm{Cr}$ (VI) adsorption on prepared AC sample. This model assumes that the rate of sites occupation is proportional to the square of unoccupied sites [18]. The linear PSO kinetic equation is presented as:

$$
\frac{t}{Q_{t}}=\frac{1}{k_{2} Q_{e}^{2}}+\frac{1}{Q_{e}} t
$$

Figure $3 \mathrm{~F}$ illustrates the graph of linear plot obtained for ${ }^{t} / Q_{t}$ against $t$ (minutes), and the constants of PSO $\left(h, Q_{e} \&\right.$ $k_{2}$ ) were determined and presented in Table 2 .

The values obtained for $\mathrm{R}^{2}[\mathrm{pH}(2)=0.991, \mathrm{pH}(4)=$ 0.983, $\mathrm{pH}(6.5)=0.992, \mathrm{pH}(9)=0.998, \mathrm{pH}(11)=0.994]$ indicates that $\mathrm{Cr}$ (VI) adsorption at varying $\mathrm{pHs}$ are consistent with the pseudo-second-order kinetics. The values obtained for $h$ indicated that $\mathrm{pH}(2)>\mathrm{pH}(4)>\mathrm{pH}(6.5)>\mathrm{pH}$ (9) $>\mathrm{pH}$ (11) which implies that $\mathrm{Cr}$ (VI) adsorption on AC400 in an aqueous solution at $\mathrm{pH}$ of 2 proceeded quite faster than $\mathrm{pH}$ of 4 .

Table 2. Isotherm constants for PFO and PSO Kinetic Model for Cr (VI) on AC400.

\begin{tabular}{llllll}
\hline Parameters & $\mathbf{p H}(\mathbf{2})$ & $\mathbf{p H}(\mathbf{4})$ & $\mathbf{p H}(6.5)$ & $\mathbf{p H}(\mathbf{9})$ & $\mathbf{p H}(\mathbf{1 1})$ \\
\hline PFO kinetics & & & & & \\
$\mathrm{k}_{1}(1 / \mathrm{min})$ & 0.0218 & 0.0212 & 0.0278 & 0.0135 & 0.0283 \\
$\mathrm{Q}_{\mathrm{e}}(\mathrm{mg} / \mathrm{g})$ & 5.247 & 5.342 & 7.359 & 2.211 & 1.856 \\
$\mathrm{R}^{2}$ & 0.934 & 0.911 & 0.911 & 0.911 & 0.929 \\
PSO kinetics & & & & & \\
$\mathrm{K}_{2}(1 / \mathrm{min})$ & 0.0028 & 0.0019 & 0.0022 & 0.0107 & 0.0103 \\
$\mathrm{~h}(\mathrm{mg} / \mathrm{g} \mathrm{min})$ & 0.0886 & 0.0690 & 0.0612 & 0.0579 & 0.0429 \\
$\mathrm{Q}_{\mathrm{e}}$ & 5.646 & 6.008 & 5.291 & 2.327 & 2.045 \\
$\mathrm{R}^{2}$ & 0.991 & 0.983 & 0.992 & 0.998 & 0.994 \\
\hline
\end{tabular}

\subsubsection{Adsorption Mechanism}

During a typical adsorption process, the transfer of the solute is generally characterized by either intraparticle diffusion or external mass transfer or both. The rate-limiting step in adsorption is predicted by the adsorption mechanism and this provides an appreciation of the mechanism associated with the phenomena. Generally, the mechanisms that influence the adsorption process include boundary layer surrounding the adsorbent or metal ion from the bulk liquid to the liquid film. Also relevant to the mechanism is the transport of solute from the boundary film to the external surface of the adsorbent and subsequently onto the active sites.

(1). Intra-Particle Diffusion (IPD)

Intra-particle diffusion was formulated by Weber and 
Morris in 1963 to predict the rate controlling step [18] which asserts that when the mass transfer is the controlling step, it is vital to determine the diffusion mechanism. The Weber/ Morris equation for intra-particle diffusion is presented as:

$$
Q_{t}=k_{i d} t^{1 / 2}
$$

A plot of $\mathrm{Q}_{\mathrm{t}}$ against $t^{1 / 2}$ at different $\mathrm{pH}$ values for $\mathrm{AC} 400$ (Figure $3 \mathrm{G}$ ) presented multiple linear characteristics with double step experienced in the adsorption process. The IPD model constants were calculated and presented in Table 3.

The steep first portion indicates high adsorption rate of $\mathrm{Cr}$ (VI) due to a larger surface area and numerous adsorption sites. The gently rise in the second portion may be attributed to the lower concentration gradient which makes the diffusion of the adsorbate into the pores of the AC sample. As $\mathrm{pH}$ shifts from 11 to 2, the steeper slopes confirm higher adsorption of $\mathrm{Cr}$ (VI) at more acidic media. The higher value of $k_{i d}$ for the AC sample at varying pHs correspond to lower values of $k_{2}$ indicating that intra-particle diffusion retards the adsorption process [19]. This seeks to postulate that Cr (VI) adsorption is very complex and involves more than one diffusion mechanism.

(2). Boyd Model

Further to Intra-particle diffusion, Boyd model was used to analyze the actual rate controlling step involved in the adsorption of $\mathrm{Cr}$ (VI) by AC400. The applied Boyd kinetic equation is presented as:

$$
F=\frac{6}{\pi^{2}} \exp (-B t)
$$

A graph of $[-0.4977-\operatorname{In}(1-F)]$ was plotted against time, $\mathrm{t}$ (minutes) to evaluate the linearity of the experimental data (Figure $3 \mathrm{H}$ ). This indicates whether external transport or intra-particle transport controls the rate of adsorption of $\mathrm{Cr}$ (VI) [19]. Obtaining a straight line through the origin indicates that the adsorption process is governed by particle diffusion mechanisms. The reverse holds true for adsorptions governed by film diffusion [20]. Also, presented in Table 3 are the result of calculated Boyd kinetics constant for $\mathrm{Cr}$ (VI) adsorbed on AC400 at varying $\mathrm{pH}$.

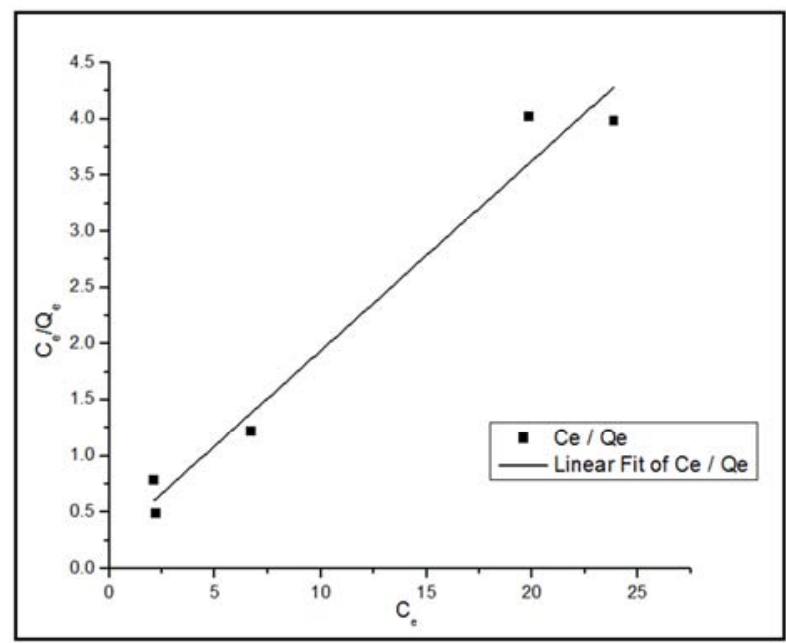

A: Langmuir isotherm of AC400 for $\mathrm{Cr}(\mathrm{VI})$ adsorption at $30^{\circ} \mathrm{C}$

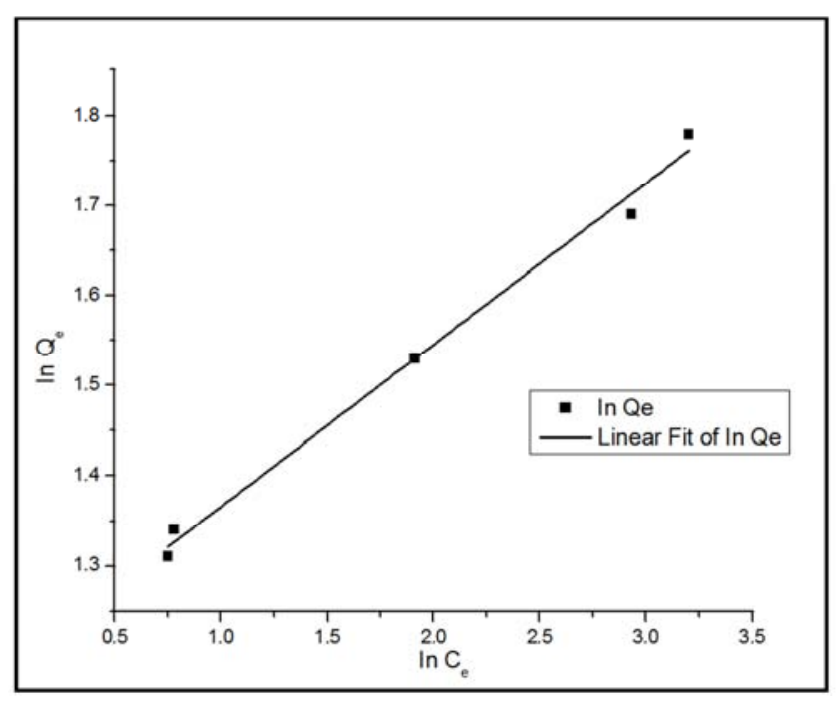

B: Linear Freundlich isotherm of $\mathrm{AC} 400$ for $\mathrm{Cr}(\mathrm{VI})$ adsorption data at $30^{\circ} \mathrm{C}$

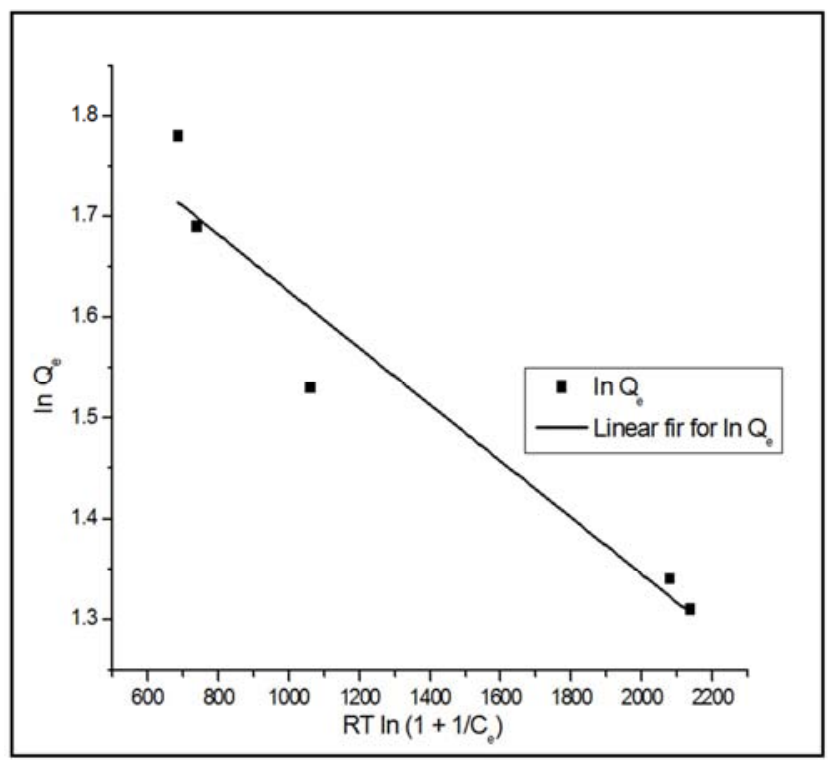

C: Linear D-R isotherm of $\mathrm{AC} 400$ for $\mathrm{Cr}(\mathrm{VI})$ adsorption data at $30^{\circ} \mathrm{C}$

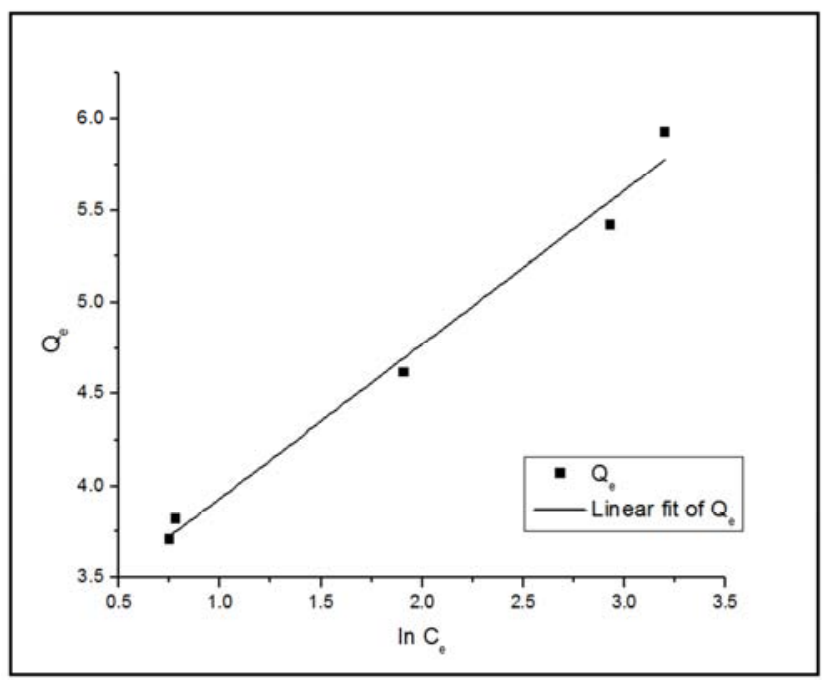

D: Temkin isotherm of AC400 for $\mathrm{Cr}(\mathrm{VI})$ adsorption data at $30^{\circ} \mathrm{C}$ 


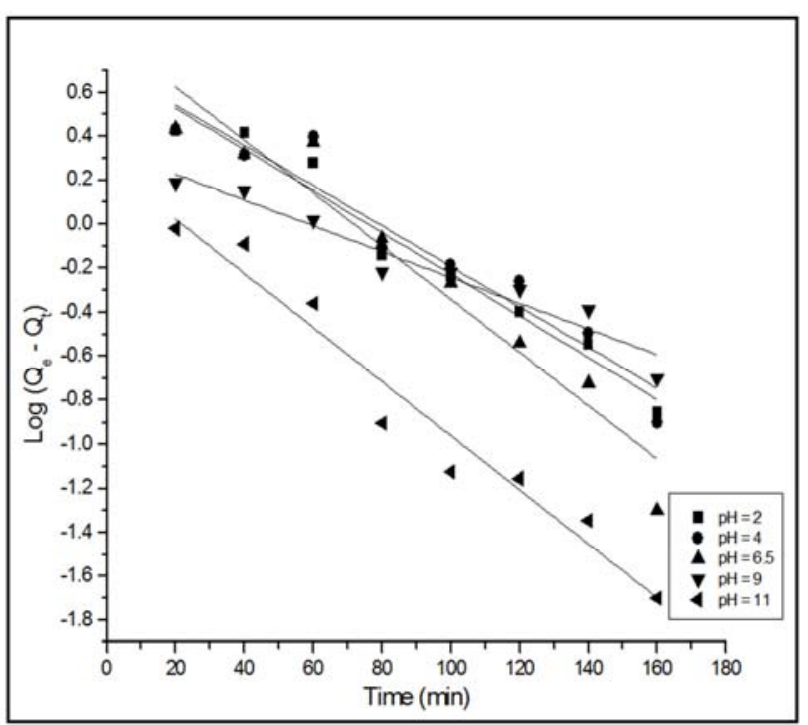

E: Lagergren PFO kinetics for $\mathrm{Cr}(\mathrm{VI})$ adsorption on $\mathrm{AC} 400$ at varying $\mathrm{pH}$

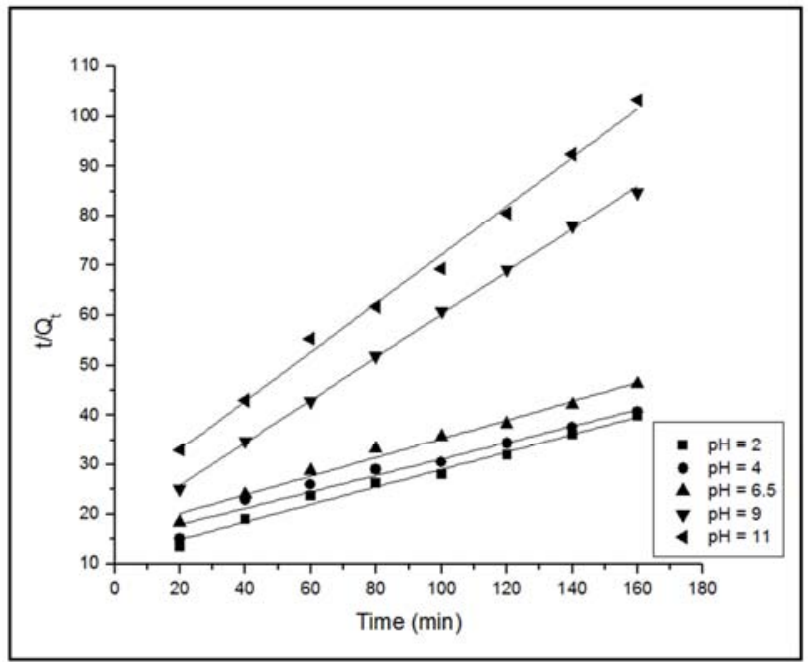

F: PSO kinetics for $\mathrm{Cr}(\mathrm{VI})$ adsorption on $\mathrm{AC} 400$ at varying $\mathrm{pH}$

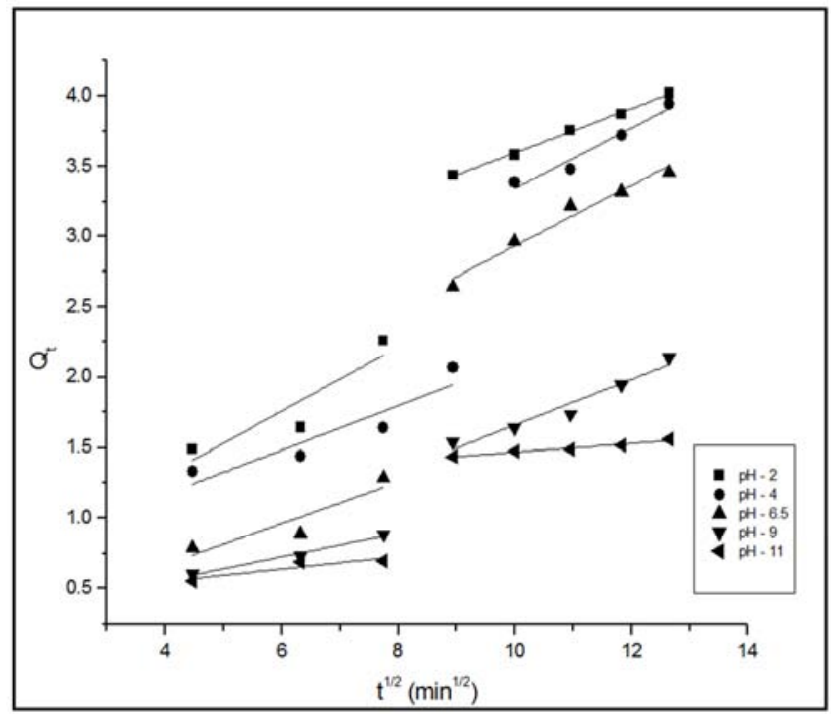

G: Intra - Particle Diffusion Model for $\mathrm{Cr}(\mathrm{VI})$ adsorption on $\mathrm{AC} 400$ at varying $\mathrm{pH}$

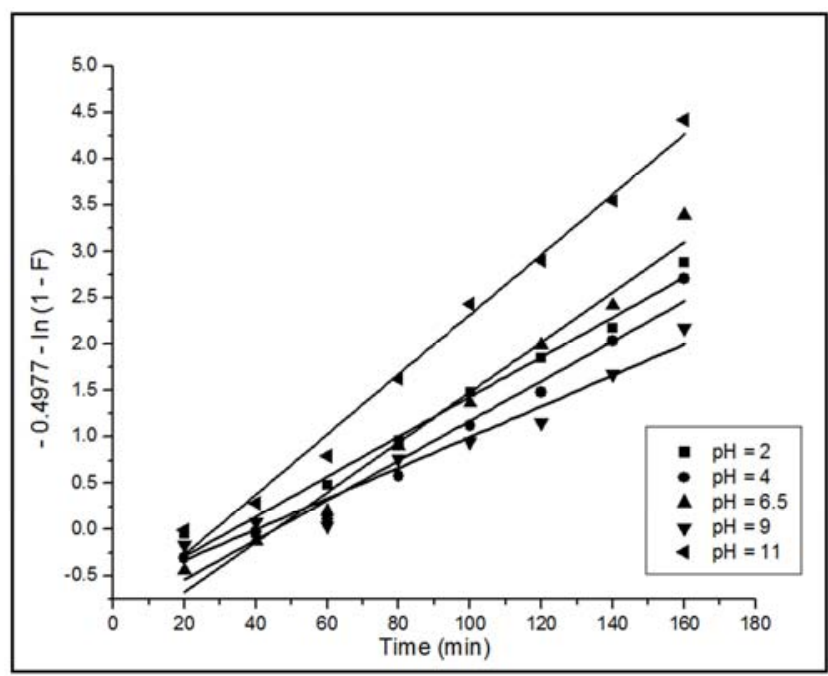

H: Boyd Kinetic Model for $\mathrm{Cr}(\mathrm{VI})$ adsorption on $\mathrm{AC} 400$ at varying $\mathrm{pH}$

Figure 3. $(A-H)$ Adsorption experimental data (A: Linear Langmuir Isotherm, B: Linear Freundlich Isotherm, $C: D-R$ Isotherm, D: Temkin Isotherm, E: Pseudo-first-order kinetics, F: Pseudo-second-order kinetics, G: Intra-particle diffusion model, $\mathrm{H}$ : Boyd Model) of AC400 for Cr (VI) adsorption data at $30^{\circ} \mathrm{C}$.

Using the calculated average diameter of adsorbent as 1.2 $\mathrm{mm}(\mathrm{r}=0.6 \mathrm{~mm})$, the diffusion coefficient, $D_{i}\left(\mathrm{~m}^{2} / \mathrm{g}\right)$ was determined for each $\mathrm{pH}$ as presented in Table 3. Based on the result obtained from Figure $3 \mathrm{H}$, it can be obtained that none of the Boyd plots for $\mathrm{pH}(2), \mathrm{pH}(4), \mathrm{pH}(6.5), \mathrm{pH}$ (9) and $\mathrm{pH}$ (11) pass through the origin which postulates that for $\mathrm{AC} 400$, film diffusion is the rate-limiting step for $\mathrm{Cr}(\mathrm{VI})$ adsorption. The values obtained for the correlation coefficient $\left(\mathrm{R}^{2}\right)$ were very close to unity (1) and adequately fits the Boyd model.

Table 3. Calculated Isotherm constant for IPD and Boyd Model.

\begin{tabular}{llllll}
\hline $\begin{array}{l}\text { Isotherm } \\
\text { Parameters }\end{array}$ & $\mathbf{p H}(\mathbf{2})$ & $\mathbf{p H}(\mathbf{4})$ & $\begin{array}{l}\mathbf{p H} \\
\mathbf{( 6 . 5 )}\end{array}$ & $\mathbf{p H}(\mathbf{9 )}$ & $\begin{array}{l}\mathbf{p H} \\
\mathbf{( 1 1 )}\end{array}$ \\
\hline $\mathrm{IPD}$ & & & & & \\
$\mathrm{K}_{\mathrm{id}}(\mathrm{mg} / \mathrm{g} \mathrm{min}$ & \\
$\mathrm{R}^{2}$ & 0.192 & 0.186 & 0.182 & 0.123 & 0.0377 \\
$\mathrm{~B}$ oyd Model & 0.841 & 0.863 & 0.819 & 0.946 & 0.814 \\
$\mathrm{~B}$ & & & & & \\
$\mathrm{Di} \times 10^{-9}\left(\mathrm{~m}^{2} / \mathrm{g}\right)$ & 0.0216 & 0.0215 & 0.027 & 0.0166 & 0.032 \\
$\mathrm{R}^{2}$ & 0.067 & 0.049 & 0.028 & 0.0259 & 0.028 \\
\hline
\end{tabular}

\section{Conclusion}

The prepared AC showed significantly high porous characteristics when applied under various qualitative and quantitative spectroscopic analysis. The adsorption of $\mathrm{Cr}$ (VI) under various process parameters indicated $\mathrm{pH}$ as the most important parameters with changes in $\mathrm{pH}$ values drawing significant variation $\mathrm{s}$ in the $\%$ adsorption and $\mathrm{Q}_{\mathrm{e}}$. Applying various isotherms to the experimental data showed consistent fit $(\mathrm{R} 2>0.99)$ with Freundlich, pseudo-second-order kinetic and Boyd models. These illustrate that the adsorption process is feasible with reversible adsorption characteristics. Also, the data postulate that adsorption proceeded much quicker in lower $\mathrm{pH}$ with film diffusion as the rate-limiting step for $\mathrm{Cr}$ 
(VI) adsorbed on AC400.

\section{Acknowledgements}

The authors gratefully acknowledge the support of those who reviewed this paper and provided many valuable suggestions. This work was financially supported by the National Natural Science Foundation of China (Grant Nos. 51778393, 51278523). Financial support was also provided by the Collaborative Innovation Center of Water Treatment Technology and Material of Jiangsu Province.

\section{References}

[1] Gautam, R. K., Sharma, S. K., Mahiya, S., and Chattopadhyaya, M. C. (2015). Contamination of Heavy Metals in Aquatic Media: Transport, Toxicity and Technologies for Remediation. In Heavy Metals In Water: Presence, Removal and Safety (pp. 1-24).

[2] Jaishankar, M., Mathew, B. B., Shah, M. S., and Gowda, K. R. S. (2014). Biosorption of Few Heavy Metal Ions Using Agricultural Wastes. Journal of Environment Pollution and Human Health.

[3] Rahman, M. M., Adil, M., Yusof, A. M., Kamaruzzaman, Y. B., and Ansary, R. H. (2014). Removal of heavy metal ions with acid-activated carbons derived from oil palm and coconut shells. Materials, 7 (5), 3634-3650.

[4] Chen, J., Zhang, L., Yang, G., Wang, Q., Li, R., and Lucia, L. A. (2017). "Preparation and characterization of activated carbon from hydrochar by phosphoric acid activation and its adsorption performance in prehydrolysis liquor," BioRes. 12 (3), 5928-5941.

[5] Song J, Wang L, Song G. (2014). Research on influence factors on determination of specific surface area of carbon material by $\mathrm{N} 2$ adsorption method. Journal of applied science and engineering innovation Vol. 1 No. 1

[6] Raj K Vyas, Shashi \& Surendra Kumar (2014). Determination of micropore volume and surface area of zeolite molecular sieves by D-R and D-A equations: A comparative Study. Indian Journal of Chemical Technology, Vol. 11, pp. 704-709.

[7] Tongpoothorn, W., Sriuttha, M., Homchan, P., Chanthai, S., and Ruangviriyachai, C. (2011). Preparation of activated carbon derived from Jatropha curcas fruit shell by simple thermo-chemical activation and characterization of their physic-chemical properties. Chemical Engineering Research and Design, 89 , p. 335-340.

[8] Zhao, J., Yang, L., Li, F., Yu, R., and Jin, C. (2009). Structural evolution in the graphitization process of activated carbon by high-pressure sintering. Carbon, 47, 744-751.
[9] Acharya, J., Sahu, J. N., Sahoo, B. K., Mohanty, C. R., and Meikap, B. C. (2009). Removal of chromium (VI) from wastewater by activated carbon developed from Tamarind wood activated with zinc chloride. Chemical Engineering Journal, 150 (1), 25-39.

[10] Al-Jabari, Maher (2016). Kinetic model for adsorption on mineral particles comparison between Langmuir kinetics and mass transfer. Journal of Environmental Technology \& Innovation 6, pp. 27-37.

[11] Wu, Q., Zhao, J., Qin, G., Wang C., Tong, X., Xue, S. (2013). Photocatalytic reduction of $\mathrm{Cr}$ (VI) with $\mathrm{TiO} 2$ film under visible light. Applied Catalysis B: Environmental, Vol. 142143, pp. 142-148.

[12] Yang, J., Yu, M., \& Qiu T. (2014). Adsorption thermodynamics and kinetics of $\mathrm{Cr}(\mathrm{VI})$ on KIP210 resin.

[13] Cao, R., Fan, M., Hu, J., Ruan, W., Wu, X., \& Wei, X. (2018). Artificial Intelligence Based Optimization for the Se (VI) Removal from Aqueous Solution by Reduced Graphene Oxide-Supported Nanoscale Zero-Valent Iron Composites. US National Library of Medicine: National Institute of Health. Vol. 11 (3), pp. 428.

[14] Youssef, S., El-Khouly S., \& El-Nabarawy T. H. (2008). Removal of $\mathrm{Pb}$ (II) and $\mathrm{Cd}$ (II) from aqueous solution using activated carbons from pecan shells: Carbon Lett, 9, pp. 8-13.

[15] Ayawei N., Ebelegi A. N., \& Wankasi D. (2017). Modelling and Interpretation of Adsorption Isotherms. Journal of Chemistry, Volume 1, ArticleID 3039817, pp. 1 -11.

[16] Boudrahem, F., Aissani-Benissad, H., and Aït-Amar, (2009). Sorption dynamics and equilibrium for the removal of lead ions from aqueous phase using activated carbon from coffee residue activated with $\mathrm{ZnCl}_{2}$. Journal of Environmental Management, 90, p. 3031- 3039.

[17] Karthikeyan, S., Balasubramanian, R., and Iyer, C. S. P. (2007). Evaluation of the marine algae Ulva fasciata and Sargassum sp. For the biosorption of $\mathrm{Cu}$ (II) from aqueous solutions. Bioresource Technology, 98 (2), p. 452-455.

[18] Sankar, K. R., Venkatraman B. R., \& Arivoli S. (2013). Equilibrium and Thermodynamic Studies on the Removal of Iron (III) onto Plater of Paris. International Journal of Engineering Innovation \& Research, Vol. 2, ISSN: 2277-5668.

[19] Wang, L., Zhang, J., Zhao, R., Li, Y., Li, C., and Zhang, C. (2010). Adsorption of $\mathrm{Pb}$ (II) on activated carbon prepared from Polygonum orientale Linn: kinetics, isotherms, $\mathrm{pH}$, and ionic strength studies. Bioresource Technology, p. 5808-5814.

[20] Doke, K. M., Khan, E. M. (2017) Equilibrium, Kinetic and diffusion mechanisms of $\mathrm{Cr}$ (VI) adsorption onto activated carbon derived from wood apple shell. Journal of Chemistry, Vol. 10, pp. S252-S260. 